\title{
Some Discussions about the Effective Path for the Reform of Education, Teaching and Connotation Quality Construction in Local engineering and Polytechnic Universities in the New Era
}

\author{
Zuo Yuxi, Yuan Yong, Yao Hongtao*, Lv Wenhao \\ Academic Affairs Department \\ Shenyang Jianzhu University \\ Shenyang, China \\ zyx.pp@foxmail.com
}

\begin{abstract}
China's higher education has gradually entered the universalization stage. With the method of empirical research, this article is based on the teaching reform practice of certain $\mathbf{J}$ University, and analyzes the characteristics of higher education in the new era, and further discusses the effective path to improve the connotative quality of local engineering and polytechnic universities from four aspects providing a new view to similar colleges and universities to meet the same challenges for reference. This article believes that local engineering and polytechnic universities should base on their own history of development, educational advantages, and school characteristics, and improve the connotation quality to respond to new challenges in four aspects: structural adjustment of specialty, professional education assessment and accreditation, informatization of education reform, and applied talents cultivation.
\end{abstract}

Keywords-Local engineering and polytechnic universities; Specialty structural adjustment; Education assessment and accreditation; Informatization of education reform; Education quality

\section{INTRODUCTION}

The "19th CPC National Congress" pointed out that "Strengthening education is fundamental to our pursuit of national rejuvenation. We must give priority to education, further reform in education, speed up its modernization, and develop education that people are satisfied with" [1]. The development of higher education should focus on solving the problems of lack of high quality talents, unbalanced distribution of educational resources etc., and constantly meet the needs of national development and people [2]. With the increasing investment in higher education and the deepening comprehensive reform of education, there was a substantial increase in the level of popular higher education. In 2014, the gross enrollment rate of higher education (GER) in Liaoning Province has reached 50.5\%. As of year 2015, GER in Beijing, Shanghai, Tianjin, Liaoning, Jiangsu, and Zhejiang provinces and cities had exceeded 50\% [3]. In 2016, GER in the country was $42.7 \%$ [4]. According to Martin Trow's theory, it is close to $50 \%$ of the threshold that indicates China's higher education has gradually become the universalization stage. Higher education in terms of allocation of resources, talent supply, teaching mode had changed comparing with the elite and popular education stages. With the stage of higher education development shift, the demand for higher education has also undergone a change, that is, from "college" to "good college".

In the new era, the main task of the development of higher education has shifted from a denotation of the expansion of the number and space to a connotation construction with the core of improving the quality of content and optimizing the structure [5]. As a local engineering university, we must strive to expand high-quality resources, rationally allocate limited resources, actively promote the internationalization of higher education, effectively improve the quality of education, and finally achieve the modernization of education with connotative development. Faced with the new normal of social economy, the upgrading of the construction industry structure, and the new round of rejuvenating Northeast China old industrial bases, it should take the initiative and actively change in the specialty structure and talents supply structure of the university

\section{STRUCTURAL ADJUSTMENT OF SPECIALTY SUPPORTS} SOCIAL ECONOMIC TRANSFORMATION AND DEVELOPMENT

Talent cultivation is the basic function of higher education in its three functions. In the process of socio-economic transformation and development, it undertakes the task of cultivating talents for industrial transformation and upgrading. Optimizing the supply structure of talents is an important means for higher education to serve the development of the society and economy better, and also an important way to realize the feature of education for economic development. The industrial structure is the basis of economic development and the main factor in promoting economic development. Human capital is the core power [6]. On August 31, 2016, Minister of Education Chen Baosheng made a State Council "Report on the Reform and Development of Higher Education" at the 22nd Session of the Standing Committee of the Twelfth National People's Congress. The report involved eight key tasks, two of 
which are to optimize the structure of higher education and deepen the quality of education reform [7]. Liaoning Province had issued an implementation opinion on adjusting the supply structure of talents. It pointed out that by 2020 the number of higher education institutions in the province will be reduced by 15; it will cancel 79 specialties (accounting for $11.93 \%$ of 662 ) of 39 undergraduate programs and increase 18 undergraduate majors [8]. In the Liaoning Province "13th Five-Year Plan" talent training program, it will also expand the enrollment of 39 specialties while reduce 31 [9].

Facing the important changes in the national economic development in the new era, it is an important task for local colleges and universities to reform the education modes to meet requirements of Ministry of Education and Department of Education, which are adjustment of the specialty structure and optimization of the talents supply. Taking J University as an example, since 2015, the adjustment of the specialty structure has been done. There have been two new specialties that serve the national "Belt and Road" policy and five specialties have been suspended for poor quality of employment and weak social demand. In 2017, while keeping the total enrollment unchanged, we actively expanded a specialty that met the demands of local industry development, cultivated serviceoriented application-oriented talents, and reduced 8 specialties with unclear services and low employment rates.

The optimization of the specialty layout structure not limited to increase or decrease the total amount, but more importantly, it is structurally systematically optimized. J University is characterized by the disciplines of architecture, civil engineering, and mechanical engineering. It was originally attached to the Ministry of Construction. The major of $75 \%$ all undergraduates is engineering. The university gradually condense out of architecture, civil engineering, mechanical and electrical, construct management and accounting four major specialty clusters. One or two colleges as the platform, one or several similar specialty categories as the basis, and one or more predominant and distinctive specialties as the core target, the university combines several related majors which have the same engineering objects, similar technical fields, and common disciplines to form a "specialty group". Each major within the group generally has the same or similar subject basis, and has a common basic curriculum. The educational and professional background of teachers is similar or related, and there are common or related requirements for the practice training platform. Affected by the unbalanced development of the regional economy, the educational resources of local colleges and universities have a large gap. Compared with the "project985", "Double First-Class" and other affiliated colleges and universities, local engineering and polytechnic universities are extremely limited in funds, personnel, facilities, equipment and teaching venues, etc. Therefore, with specialized groups as the unit, it will promote the construction of advantageous and featured specialties, complement the complementary resources, and share curriculum resources, teachers, practical training platforms, etc. Finally those will help to improve the efficiency use of educational resources.

\section{TO STRENGTHEN THE CONNOTATION CONSTRUCTION BY MEANS OF PROFESSIONAL EDUCATION EVALUATION}

The guarantee of education quality must rely on two major systems: quality management system and effective supporting system. The former, such as ISO 2015, includes outcome-based education, student-centered, and the quality improvement for education. It is also the core essence of engineering education accreditation and undergraduate education assessment. The latter includes general education resources such as teachers, campuses, equipments, and funds, but the key is specific teaching resources such as curriculum, course book, and practice teaching base, etc.

The object of professional education assessment and accreditation is a specific specialty, mainly including teaching conditions, cultivating process, cultivating achievements and so on. The training standards of engineering programs are generally formulated by the industry, and jointly implement the assessment process, which strongly reflects the needs of the industry. Professional education assessment and accreditation is targeted and efficient approach. It is an external evaluation. According to its own conditions, the higher education institution voluntarily chooses whether or not to participate in the evaluation. Based on the standards for Professional assessment, it conducts self-inspection on the conditions for the overall management, the quality of the education, the education process, and conducts self-examination and self-assessment to achieve the goal of improvement.

Due to factors such as the history, the scale, the type, and the fundamentals, serving local economic development and cultivating talents focused on specific industries are the main features of local colleges and universities. Taking J University as an example, relying on its profound civil engineering and architecture discipline foundation, in the 1990s, the civil engineering and architecture education assessment had carried out by the former Ministry of Construction (now the Ministry of Housing and Urban-Rural Development) and linked to vocational qualification system. Following the guideline of "Promoting Development by Evaluation and Integrate Evaluation and Development", after more than 20 years of assessment and development, all six professional assessments carried out by the Ministry of Housing and Urban-Rural Development were completed with the maximum validity period. Since China's accession to the Washington Accord in 2016, qualified by engineering education accreditation, equivalent to international engineering education has become an important means for domestic universities to improve the quality of engineering education and the internationalization of talent certification. The basic concept of outcome-based education, student-centered, and the quality improvement of engineering education has been widely accepted by engineering colleges and universities; consensus has been formed within the administrators. The engineering education reform guided by the engineering education accreditation has pointed out the direction for the engineering specialty construction and improving the quality of engineering education. 
Based on professional education assessment and accreditation standards, the education and teaching process will be meticulously designed with self-inspection; the shortcomings of the talent cultivation process will be found and improved timely. Overall progress has effectively elevated the level of specialty construction and improved the quality through the comprehensive curriculum construction, practical teaching reform, faculty development, discipline construction, students work, etc. The professional education assessment and accreditation has made a great achievement, and the education quality has been greatly improved. Graduates have received wide acclaim from employers, further enhancing the school's social reputation and expanding its influence in the industry.

\section{TO PROMOTE THE TRANSFORMATION OF TEACHING MODE BY EDUCATIONAL INFORMATIONIZATION}

The Ministry of Education's "10 Year Development Plan for Education Informationization (2011-2020)" proposes that "informatization education should be used to promote education modernization." The effective integration of information technology in the teaching process could create an information-based teaching environment, change the traditional teaching model, highlight the main learning roles, and so that students would have abilities of the initiative, enthusiasm, and creativity to achieve the purpose of capacity development. At the same time, information technology will help teachers in curriculum design and form a new teaching and learning mode characterized by "independence, exploration, and cooperation." In the "Internet Plus" era, technologies such as cloud computing, big data technology, Internet of Things, and Mobile Internet have made the more extensive education and teaching elements connected, broken the traditional teaching mode, and produced a revolutionary change. Classroom instruction shifts from traditional knowledge-instilling teaching to studentcentered discovery learning; teacher's role changes from classroom leader to student's learning activity guide; teaching model transfers from single teaching to mixed interactive discussion; teaching content consists of the transformation of textbooks into interactive resources with the diversity. Through the teaching informationization reform, the student-centered education is being implemented in a more flexible and rich way, which provides an effective path for classroom teaching reform in colleges and universities.

There is an obvious gap between local universities and affiliated universities, such as education resources, faculties, and students' quality, especially in the allocation of highquality teaching resources. Through the education informationization reform, it will help improve the use of educational resources, reduce the cost of education, and narrow the gap between schools. Therefore, in the new wave of educational informationization reform, local colleges and universities must seize the opportunity to actively promote the reform of education and optimize the allocation of educational resources. In the implementation phase, that would be mainly the informatization construction of the classroom and the informatization of examination. As local universities, we should vigorously promote open online courses and crossschool study credits to optimize the use of resources. At the basic-level College or school level, according to the characteristics of the curriculum, the standard computer-based examination and artificial intelligence correcting should be promoted and attempted. In practice teaching, the construction of virtual labs has become the focus of information reform. The use of new information technology means to replace traditional experimental operations those had potentially dangerous; the virtual experiments is conducive to improving the safety of the experiments. As for practical teaching which needs more complex site requirements and higher equipment requirements, the virtual platform is conducive to guaranteeing the time. With stable operation, that also saves practical teaching expenses and improves resource utilization.

\section{TRANSFORMATION AND DEVELOPMENT TO CULTIVATE APPLIED TALENTS}

As the socio-economic structure is in a transitional phase, the talent demand is also changing. Whether to solve the employment problem of graduates or to promote the transformation of talent supply types, transitional development is an urgent task for local colleges and universities. In this process, the government is the condition initial creator, the industrial is the important participant and the higher education institution is the decision-making and responsible subject [10]. Liaoning Province, in 2015, issued the implementation opinions to promote the transition application-oriented universities, and selected batches of pilot colleges and universities and majors for application-oriented transformation. On that basis, it further filtered out model institutions and majors in 2017. Five specialties in J University have been approved for provincial-level application transformation pilot programs. The 24 engineering majors also have applicationoriented features for engineering practice. Based on the overall planning, the J University further rationalized the relationship between first-class discipline construction and applicationoriented transformation, and then began to explore multispecies and diversified application-oriented cultivating models: connect with industry applications, promote the integration quality of production and education, deepen the cooperation between universities and enterprises, introduce industry experts into the training scheme revising process, achieve an in-depth understanding of business needs, consolidate students' core abilities, and adjust the orientation of education. At the same time, the "university-enterprise cooperation education plans" is adopted. The enterprise technicians and university teachers jointly guide students in graduation practice, graduation design etc., and also perform comprehensive practical teaching in a real engineering environment, which is conducive to the cultivation of students' engineering practice abilities; faculties are also actively involved in the production practice, accumulating experience in engineering practice and improving the ability of engineering practices.

The university has established long-term and stable cooperative relations with a number of large-scale state-owned enterprises, resulting customized classes and several joint practical teaching bases. The enterprises selected a variety of specialties students to a mixed class. Keeping the cultivation of the original specialties unchanged, corporate culture, enterprise management, industry enterprise standards and latest technology are added to the classes, those introduce entry 
education into the undergraduate teaching process in advance. Graduation and effective employment are seamlessly matched. During the summer or winter vacation, the company arranges practical teaching links such as internships and camp training to help to finally select the excellent candidates.

\section{CONCLUSION}

In new era, the trend of higher education development has changed. Local engineering and polytechnic universities must take the initiative to meet the challenges, combine their own development history, advantages, and self-characteristics, and explore the effective path to improve the connotation quality. By improving the quality of education with the limited educational resources, local engineering and polytechnic universities could serve the regional socio-economic development better and cultivate more high-quality talents to satisfy the needs of the industry.

\section{REFERENCES}

[1] Xi Jinping. Secure a Decisive Victory in Building a Moderately Prosperous Society in All Respects and Strive for the Great Success of Socialism with Chinese Characteristics for a New Era [N]. People's Daily, 2017-10-28.(In Chinese)

[2] Li Yuanyuan. Opening a new era of higher education new journey [N]. People's Daily, 2017-11-22 (07 edition). (In Chinese)

[3] Qin Fuli. Review and Reflection on the Gross Enrollment Rate fo Higher Education in China at the Present Stage --Based on the Analysis of the Last Three Five-Year Plan for the Development of Education in Various Regions [J]. Education Science, 2017, 33(6): 43-49. (In Chinese)

[4] Education in China: Development of National Education in 2016 $[\mathrm{EB} / \mathrm{OL}]$.

[2018-5-23] http://www.moe.gov.cn/jyb_sjzl/s5990/201711/t20171110_318862. (In Chinese)

[5] Zhong Binglin. Reform of the Talent Cultivating Mode: The Key Point of Chinese Universities' Intensive Construction [J]. Journal of Higher Education, 2013, 34(11):71-76. (In Chinese)

[6] Yang Lin,Chen Shuquan,Han Keji. Analysis of the Coordination of Higher Education Discipline Structure and Industrial Structure Optimization [J]. Research in Educational Development, 2015, 21:45-51 (In Chinese)

[7] Chen Baosheng. State Council report on the reform and development of higher education - August 31, 2016 at the 22nd Session of the Standing Committee of the Twelfth National People's Congress [EB/OL].[ 20185-23].http://www.npc.gov.cn/wxzl/gongbao/201610/12/content_2007452.htm. (In Chinese)

[8] Liaoning Provincial People's Government. Liaoning Provincial People's Government Implementing Opinions on Promoting Structural Reforms on the Supply Side of High Schools [EB/OL].[2017-1-2]. http://www.lnen.cn/zwgk /zwtz/287310.shtml. (In Chinese)

[9] Liaoning Provincial Development and Reform Commission, Liaoning Provincial Department of Education. Liaoning Province, "Thirteen FiveYear Plan for Talent Cultivation in Universities [EB/OL].[2017-1-2]. http://www.upln.cn/ Html/2016/Column_0103_0725/3891.html. (In Chinese)

[10] Zhang Yingqiang, Jiang Hualin. R eflections on the Challenges Confronting China' s Municipal Colleges in Transition [J]. Modern University Education,2014,(6):1-8. (In Chinese) 